\title{
Guaiacol - a new compound in the treatment of gastro-oesophageal reflux?
}

\author{
R V HEATLEY, ${ }^{*}$ B K EVANS, J RHODES, and M ATKINSON \\ From the Departments of Gastroenterology and Pharmacy, University Hospital of Wales, Cardiff, and the \\ Department of Gastroenterology, University Hospital, Nottingham
}

SUMmARY The effects on the oesophagus of an aromatic oil, guaiacol, has been examined in a group of 20 patients with reflux oesophagitis and also normal volunteers. This agent produced a rapid and sustained rise in resting lower oesophageal sphincter pressures and the peristaltic pressures induced in response to swallowing liquids. This compound may prove useful in the treatment of patients with reflux oesophagitis and other disorders of oesophageal motility.

Aromatic oils or substances containing them have been used as internal medicinal agents from the earliest times. The therapeutic aims have been numerous but probably the most frequent has been to produce the 'carminative' effect. Carminatives are agents which produce a sensation of abdominal warmth and relieve gastrointestinal distension when ingested orally, probably by increasing gut mucosal blood flow and acting as antispasmodics. ${ }^{1-3}$ Indeed, it may have been these properties which prompted Hippocrates (460-361 BC), for example, to use oil of rue as an antispasmodic, stimulant, and rubefacient in the treatment of childhood colic.

Pharmacological studies performed on isolated preparations of mammalian smooth muscle, using known constituents of volatile oils and other chemically related agents, have demonstrated that many of these compounds decrease muscle tone and spontaneous contractility; properties which are characteristic of antispasmodics and spasmolytics. ${ }^{4}$ We have identified one aromatic oil, however, which increases spontaneous activity of isolated muscle strips in vitro and the canine colon in vivo. ${ }^{56}$ We have further examined the efficacy of this compound in the human oesophagus in normal individuals and patients suffering from gastrooesophageal reflux complicated by oesophagitis. Diminution in oesophageal peristalsis and resting tone of the lower oesophageal sphincter (LOS) are believed to contribute to the pathophysiology of reflux oesophagitis and it is likely that a topically-

\footnotetext{
* Address for correspondence: Dr R V Heatley, Department of Medicine, St James's University Hospital, Leeds LS9 7TF.

Received for publication 15 March 1982
}

acting, natural product, which improves these parameters of abnormal oesophageal motility, may prove useful in the treatment of patients with gastro-oesophageal reflux. ${ }^{78}$

\section{Methods}

\section{PATIENTS}

Twenty patients with reflux oesophagitis were studied. All patients gave a history of retrosternal burning discomfort, had demonstrable free gastrooesophageal reflux and an associated hiatus hernia at barium meal examination, and endoscopic biopsy evidence of oesophagitis without any other demonstrable pathology. Eight normal volunteers, all of whom were asymptomatic hospital staff, were also studied by manometry.

\section{MANOMETRY}

Oesophageal manometry was performed after a six-hour fast in the left lateral position using a train of three open-ended polyvinyl chloride tubes each of $1.5 \mathrm{~mm}$ internal diameter with side holes $5 \mathrm{~cm}$ apart, perfused by a syringe pump at a rate of $0.5 \mathrm{ml} / \mathrm{min}$ and connected to Statham strain gauge pressure transducers, carrier amplifiers, and a SE3006 ultraviolet light recorder. The system showed complete fidelity to a sinusoidal input of $15 \mathrm{Hertz}$ and to square pressure waves up to $60 \mathrm{~mm} \mathrm{Hg}$. Thereafter there was some attenuation, which amounted to $5 \%$ at $100 \mathrm{~mm} \mathrm{Hg}$. The rate of rise of pressure when the opening was occluded was $800 \mathrm{~mm} \mathrm{Hg} / \mathrm{s}$.

Resting lower oesophageal sphincter pressures were measured by the rapid pull-through method taking the mean of nine measurements obtained at 
three pull-throughs. The height of the peristaltic pressure wave in the lower oesophagus in response to swallowing $20 \mathrm{ml}$ of water was also measured. ${ }^{9} 10$ Further recordings were taken at intervals up to 40 minutes after oral ingestion of $20 \mathrm{ml}$ of the test solutions. Guaiacol, a colourless, odourless, and tasteless compound was given in varying concentrations, administered in an aqueous solution and control readings taken after a $20 \mathrm{ml}$ dose of water was given alone. The test and control solutions were prepared in coded bottles by the pharmacist and given to patients in random order. Pressure measurement traces were read 'blind' by two observers working together.

\section{GASTRIN LEVELS}

Serum gastrin levels were measured by radioimmunoassay in five normal volunteers after oral administration of $20 \mathrm{ml}$ 1:2500 guaiacol. ${ }^{11}$

\section{STATISTICAL ANALYSES}

Results expressed are mean recordings \pm SD and statistical comparisons have been performed using Student's $t$ test.

\section{Results}

\section{OESOPHAGEAL MANOMETRY}

LOS pressures

The resting mean LOS pressures measured in 14 patients with reflux oesophagitis were $12.5 \pm 9.1 \mathrm{~mm}$ $\mathrm{Hg}$. Five minutes after ingestion of $20 \mathrm{ml}$ of a $1: 10000$ solution of guaiacol the mean LOS pressures rose to $18.9 \pm 9.9 \mathrm{~mm} \mathrm{Hg}(\mathrm{p}<0.0005)$ (Fig. 1). In normal individuals the baseline mean LOS pressures recorded were $17.75 \pm 1.7 \mathrm{~mm} \mathrm{Hg}$ and rose after $20 \mathrm{ml}$ of $1: 10000$ guaiacol to $32.75 \pm 5.3 \mathrm{~mm}$ $\mathrm{Hg}(\mathrm{p}<0.02)$.

\section{PERISTALTIC PRESSURES}

Mean peristaltic pressure recordings taken on three recording channels after five consecutive swallows (15 readings) in 14 patients with oesophagitis are illustrated in Fig. 2. Mean baseline pressures were $24.4 \pm 5 \cdot 1 \mathrm{~mm} \mathrm{Hg}$ and rose five minutes after ingestion of $20 \mathrm{ml} 1: 10000$ guaiacol to $30.3 \pm 7.9 \mathrm{~mm}$ $\mathrm{Hg}(\mathrm{p}<0.01)$. In five patients with diffuse oesophageal spasm secondary to gastro-oesophageal reflux it was not possible to measure baseline pressures. Five minutes after guaiacol administration, the spasm had subsided sufficiently for peristaltic pressure recordings to be obtained. In nermal individuals baseline peristaltic pressures were $31.75 \pm 1.7 \mathrm{~mm} \mathrm{Hg}$ and rose after guaiacol to $39.0 \pm 6 \cdot 2 \mathrm{~mm} \mathrm{Hg}$, but the difference was not significant.

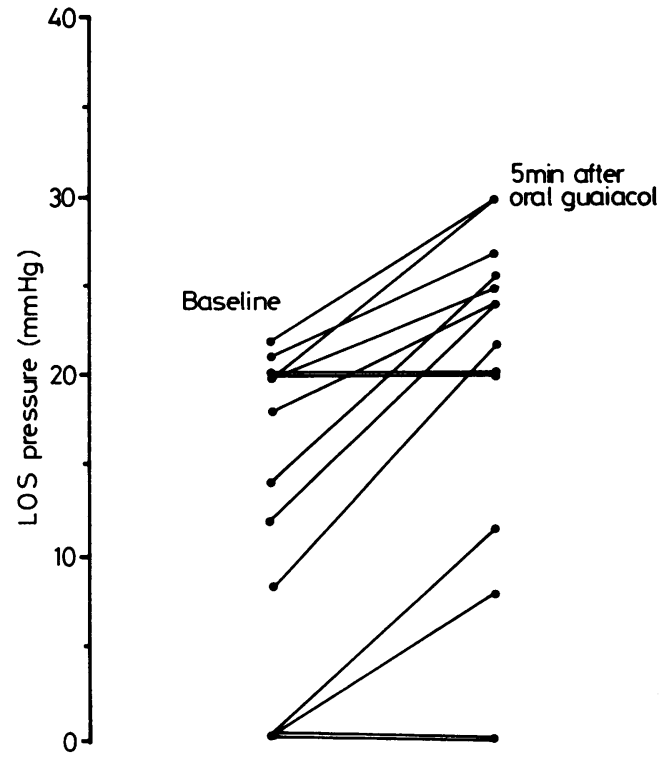

Fig. 1 Mean lower oesophageal sphincter (LOS) pressures recorded in patients with reflux oesophagitis, before and five minutes after $2 \mathrm{mg}$ guaiacol.

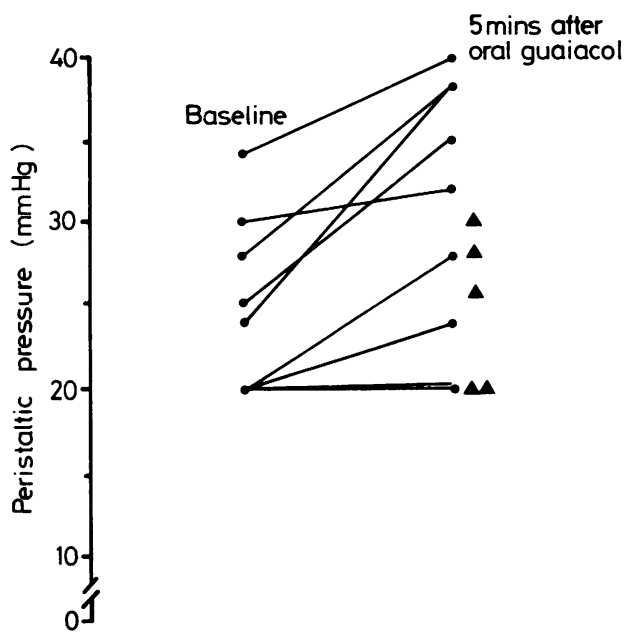

Fig. 2 Mean peristaltic pressures recorded in the lower oesophagus in response to water swallowing in patients with reflux oesophagitis, before and five minutes after $2 \mathrm{mg}$ guaiacol. $\Delta$ Pressure recordings in patients in whom peristalsis could not initially be assessed because of the presence of diffuse oesophageal spasm secondary to oesophagitis. 
The manometric effects of $20 \mathrm{ml}$ doses of differing concentrations of guaiacol in a further six subjects with reflux oesophagitis are illustrated in Fig. 3. Administration of $20 \mathrm{ml}$ of water alone to test subjects did not significantly affect the recordings. In all cases in which a manometric effect of guaiacol was observed, this occurred within two minutes after administration and persisted 40 minutes after the dose was given.

\section{SERUM GASTRIN LEVELS}

Baseline serum gastrin levels were $43 \pm 6 \cdot 2 \mathrm{ng} / \mathrm{ml}$; two minutes after guaiacol administration, $40 \cdot 8 \pm 1 \cdot 3$ $\mathrm{ng} / \mathrm{ml}$; five minutes - $43.6 \pm 6.8 \mathrm{ng} / \mathrm{ml}$; and 20 minutes after guaiacol, $40 \cdot 6 \pm 4.7 \mathrm{ng} / \mathrm{ml}$. The difference was not significant.

\section{Discussion}

The term 'carminative' is probably derived from the word, and means 'charm' and it is likely that this term aptly describes the effect these compounds have on a multitude of abdominal complaints, particularly flatulence. Indeed, peppermint oil, which contains a number of volatile oils, relaxes the lower oesophageal sphincter after oral ingestion. ${ }^{12}$ Most essential oils exert the carminative or antispasmodic effect directly on intestinal smooth muscle probably either in the same manner as local anaesthetics or parasympathomimetic agents and may influence cellular incorporation of ATP. ${ }^{13-15}$ Some of their constituents in differing doses exert a stimulatory effect on the intestine and we have identified one compound, guaiacol, which stimulates isolated muscle strips in vitro and the canine colon and human oesophagus in vivo.

This compound almost certainly acts topically on the oesophagus and colon, the duration of onset being rapid and action prolonged. As we did not observe any significant change in serum gastrin

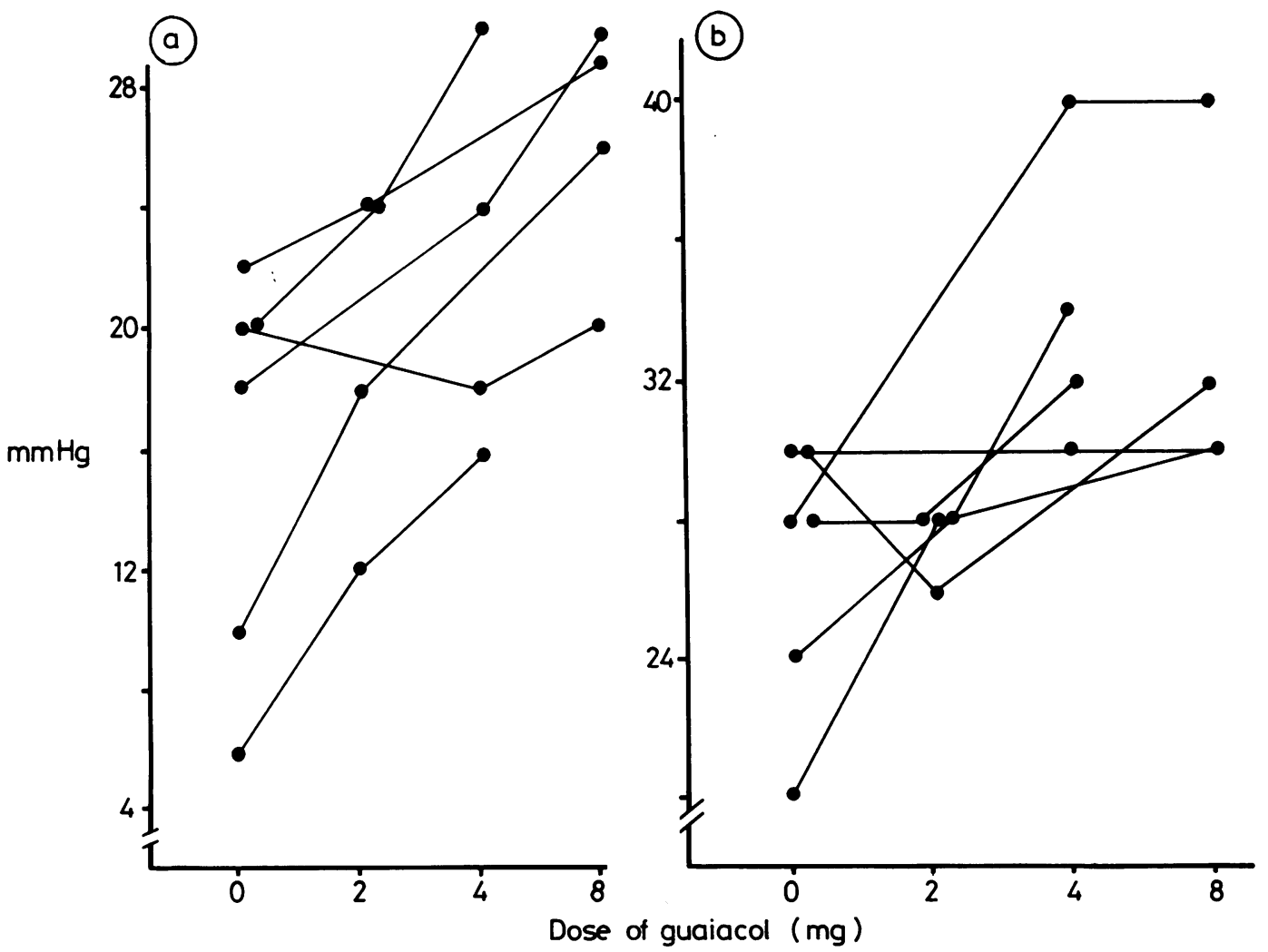

Fig. 3 Mean lower oesophageal sphincter (LOS) (a) and peristaltic (b) pressures recorded in patients with reflux oesophagitis, before and after varying oral doses of guaiacol. 
concentrations after the administration of guaiacol it is unlikely that gastrin release is the mechanism for its actions on the oesophagus. Guaiacol has been used therapeutically for many years by mouth as an expectorant and also intravenously in patients with lung abscesses, but is not in the current British Pharmacopoeia (1980) or the British Pharmaceutical Codex (1973), apparently because of lack of use rather than any clinical problems. ${ }^{16}$ This compound appears to have potent stimulatory effects on the human oesophagus that presumably have been previously unrecognised, and may prove to be of therapeutic value in the treatment of patients with gastro-oesophageal reflux, and possibly other disorders of oesophageal motility.

Reflux of acid and bile into the oesophagus due to a reduction in tone of the lower oesophageal sphincter and delayed clearing of the oesophagus due to presumed inadequate peristalsis are features believed to be important in the development of reflux oesophagitis. Attempts to correct these abnormalities of oesophageal motility have led to the use of metoclopramide in the treatment of patients with oesophagitis. This compound has been shown to increase the lower oesophageal sphincter pressure and augment the amplitude of peristaltic contractions in the lower oesophagus in normal individuals. ${ }^{17}$ Whether it exerts these effects when given orally in normal therapeutic doses to patients with gastro-oesophageal reflux, is less clear. ${ }^{18}$ It does appear to be clinically effective in this condition, but this may be because of its known action in stimulating gastric emptying and removing acid and bile from the stomach. ${ }^{19} 20$ Its use, is, however, associated with side-effects in at least $10 \%$ of patients to whom it is given therapeutically. ${ }^{21}$ There is clearly a place for an alternative safe drug treatment which improves oesophageal motility in patients with reflux oesophagitis, and it may be advantageous in this respect to have a topically active agent. Guaiacol is a naturally occurring compound which would appear to be suitable in this regard and has been extensively used for many years with apparent safety.

\section{References}

1 Gunn JWC. The carminative action of volatile oils. $J$ Pharmacol Exp Ther 1920; 16; 39-47.

2 Plant $\mathrm{OH}$, Miller $\mathrm{GH}$. Effects of carminative volatile oils on the muscular activity of the stomach and colon. $J$ Pharmacol Exp Ther 1926; 27; 149-56.

3 Creamer B. Oesophageal reflux and the action of carminatives. Lancet $1955 ; 1 ; 590-2$.

4 Evans BK, James KC, Luscombe DK. A correlation between solubility and carminative activity. $J$ Pharm Pharmacol 1972; 24; suppl 173P.

5 Evans BK, Heatley RV, James KC, Luscombe DK. Further studies on the correlation between biological activity and solubility of some carminatives. J Pharm Pharmacol 1975; 27; suppl 66P.

6 Evans BK. Physical and biological properties of carminatives. PhD thesis, University of Wales, 1980.

7 Siegel CI, Hendrix TR. Esophageal motor abnormalities induced by acid perfusion in patients with heartburn. J Clin Invest 1963; 42; 686-95.

8 Donner MW, Silbiger ML, Hookman P, Hendrix TR. Acid-barium swallows in the radiographic evaluation of clinical oesophagitis. Radiology 1966; 87; 220-5.

9 Dodds WJ, Hogan WJ, Stef JJ, Miller WN, Lydon SB, Arndorfer RC. A rapid pull-through technique for measuring lower esophageal sphincter pressure. Gastroenterology 1975; 68; 437-43.

10 Heatley RV, Collins RJ, James PD, Atkinson M. Vagal function in relation to gastro-oesophageal reflux and associated motility changes. $\mathrm{Br} \mathrm{Med} J \mathrm{1980}$; 1; 755-7.

11 Yalow RS, Berson SA. Radioimmunoassay of gastrin. Gastroenterology 1970; 58; 1-14.

12 Sigmund CJ, McNally EF. The action of a carminative on the lower esophageal sphincter. Gastroenterology 1969; 56; 13-18.

13 Abood LG, Koketsu K, Miyamoto S. Outflux of various phosphates during membrane depolarization of excitable tissues. Am J Physiol 1962; 202; 469-74.

14 Kuperman AS, Okamoto M, Beyer AM, Volpert WA. Procaine action: antagonism by adenosine triphosphate and other nucleotides. Science 1964; 144; 1222-3.

$15 \mathrm{Kehl} \mathrm{H}$. Muscle relaxant action of -hydroxylamine cinnamonyl hydroxamic acid in isolated organs. $J$ Pharm Sci 1973; 62; 723-8.

16 British Pharmaceutical Codex. London: Pharmaceutical Press, 1949.

17 Heitmann P, Moller N. The effect of metoclopramide on the gastroesophageal junctional zone and the distal esophagus in man. Scand J Gastroenterol 1970; 5; 621-5.

18 McCallum RW, Kline MM, Curry N, Sturdevant RAL. Comparative effects of metoclopramide and bethanechol on lower oesophageal sphincter pressure in reflux patients. Gastroenterology 1975; 68; 1114-8.

19 Stanciu C, Bennett JR. Metoclopramide in gastrooesophageal reflux. Gut 1973; 14; 275-9.

20 Connell AM, George JD. Effect of metoclopramide on gastric function in man. Gut $1969 ; 10 ; 678-80$.

21 Robinson OPW Metoclopramide - side effects and safety. Postgrad Med J 1973; suppl: 77-80. 